\title{
A Comparative Evaluation on the effect of Zinc-Probiotic combination versus Zinc alone therapy in children (3month-5year) with acute watery diarrhea attending the outpatient clinic of Sub-District hospital, Uttarakhand
}

\author{
Nikhurpa M. ${ }^{1 *}$, Agnihotri R. ${ }^{2}$
}

DOI: https://doi.org/10.17511/ijmrr.2021.i04.09

\footnotetext{
1* Mamta Nikhurpa, Pediatrician, District Hospital, Bageshwar, Uttarakhand, India.

2 Renu Agnihotri, Pediatrician, Female Hospital, Haldwani, Uttarakhand, India.
}

Background: Diarrhea is the major cause of morbidity and mortality among children worldwide. Various studies were done on the role of zinc therapy and probiotic therapy in reducing the duration and severity of acute watery diarrhea. This study aimed to compare the effect of Zinc -probiotic combination versus Zinc only therapy in acute watery diarrhea in pediatric patients. Material and Methods: This was an open, randomized control trial in the pediatric outpatient department of SubDistrict Female Hospital, Haldwani (Uttarakhand), from June 2020 till August 2020 for three months. Total 104 children aged six months to 5 years with acute diarrhea who met the inclusion criteria were enrolled and divided into 52 patients each. $1^{\text {st }}$ Group $A(n=52)$ received Zinc-Probiotics combination therapy, and $2^{\text {nd }}$ Group $B(n=52)$ received Zinc only. Measurement of disease severity was based on the frequency of diarrhea (times/day) and duration of diarrhea (hours) after initial drug consumption. The resolution was assessed in mean remission time (time required to form solid stool from watery stool).Result: Among the study population in group A, 62\% were male, 38\% were female, and in group B, $65 \%$ were male \& $35 \%$ were female. Male predominance was observed in both groups. The mean frequency of diarrhea before treatment in Group A was $7.46 \pm 4.1$ times/day as compared to $6.69 \pm 3.6$ times/day in Group B. Mean duration of diarrhea in Group A was $53.5 \pm 30.5$ hours as compared to $57.6 \pm 34.3$ hours in Group B. Conclusion: Combination therapy was more effective than Zinc only therapy in early remission and resolution of acute watery diarrhea in children.

Keywords: Acute watery diarrhea, Zinc, Probiotics

Corresponding Author

Mamta Nikhurpa, Pediatrician, , District Hospital, Bageshwar, Uttarakhand, India.

Email: mamtanikhurpa389@gmail.com
How to Cite this Article

Nikhurpa M, Agnihotri R. A Comparative Evaluation on the effect of Zinc-Probiotic combination versus Zinc alone therapy in children (3month-5year) with acute watery diarrhea attending the outpatient clinic of Sub-District hospital, Uttarakhand. Int J Med Res Rev. 2021;9(4):263-268.

Available From

https://ijmrr.medresearch.in/index.php/ijmrr/article/

view/1307
To Browse

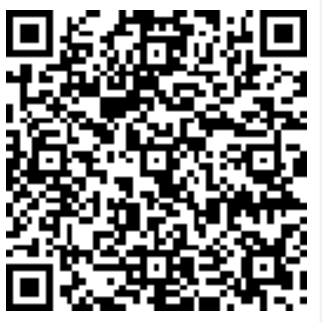

Manuscript Received 2021-07-24

Conflict of Interest No
Review Round 1 2021-07-27

Funding
Review Round 3 2021-08-18

Plagiarism X-checker $7 \%$
Accepted 2021-08-27

Ethical Approval Yes

(c) 2021 by Mamta Nikhurpa, Renu Agnihotri and Published by Siddharth Health Research and Social Welfare Society. This is an Open Access article licensed under a Creative Commons Attribution 4.0 International License https://creativecommons.org/licenses/by/4.0/ unported [CC BY 4.0]. 


\section{Introduction}

Diarrhea is the second leading cause of morbidity and mortality among children worldwide. It is responsible for nearly $10 \%$ of all deaths in children under five years of age and accounts for about 500,000 child deaths in developing countries every year $[1,2]$. Global burden and severity causing mortality are more prevalent in the first two years of life, suggesting an increased emphasis on prevention and treatment in neonates and children less than two years is crucial. Nearly a third of episodes of severe diarrhea are preventable by vaccination (i.e., against rotavirus and cholera)[3].It remains one of the most common reasons for hospital admission, with an estimated 1731 million episodes of childhood diarrhea reported in 2011, of which $2 \%$ progressed to severe disease [4]. Undernutrition is a crucial risk factor for morbidity and mortality associated with diarrhea. It is also a significant cause of malnutrition, mainly prolonged, and interventions to improve nutrition should be prioritized [5].

In 2013, the WHO and the United Nations Children's Fund (UNICEF) formulated the Integrated Global Action Plan for Pneumonia and Diarrhea (GAPPD) was launched in 2013 by the WHO and the United Nations Children's Fund (UNICEF) to devise a framework for ending preventable child deaths due to diarrhea and pneumonia by 2025 . The GAPPD emphasizes a 'protect, prevent, and treat' approach that integrates interventions with proven effectiveness. Currently, WHO recommends treatment with oral rehydration salts (ORS) and continues feeding for the prevention and treatment of dehydration, as well as Zinc to shorten the duration and severity of the episodes [6]. The World Health Organization (WHO) and UNICEF recommend daily $20 \mathrm{mg}$ zinc supplements for $10-14$ days for children with acute diarrhea, and $10 \mathrm{mg}$ per day for infants under six months old, to reduce the severity of the episode and prevent further occurrences in next two to three months, thereby decreasing the morbidity. Diarrhea is more common in children with zinc deficiency and responds quickly to zinc supplementation.

Mechanism of action of Zinc includes it restores mucosal barrier integrity and enterocyte brushborder enzyme activity, promotes the production of antibodies and circulating $T$ lymphocytes against intestinal pathogens and has a direct effect on ion channels.
In recent years, probiotics have been widely studied in preventing and treating diarrhea, particularly in the pediatric population [7]. Probiotics are living microorganisms that survive in the gastrointestinal tract and when ingested in a sufficiently large amount, provides a health benefit on the host [8]. Lactobacillus, Bifidobacterium, and non-pathogenic yeast such as Saccharomyces boulardii are some examples of commonly used probiotics. In $2010 \mathrm{~A}$ Cochrane review concluded that the probiotics tested reduced the duration of diarrhea within 24.76 hours (95\% confidence interval [CI], 15.9-33.6 hours; $n=4,555$, trials=35). According to the same Cochrane review, the frequency of stools decreased on day 2 (mean difference, 0.80; 0.45-1.14; $\mathrm{n}=2,751$, trials $=20$ ) [9] Probiotics were reported to reduce the duration of community-acquired acute diarrhea by $14.0 \%$ (95\% CI, 3.8-24.2\%) and stool frequency on the second day of treatment by $13.1 \%$ (95\% CI, 0.8-25.3\%)[10].Zinc and Probiotics work by different mechanisms to reduce the severity of acute watery diarrhea. There are very few studies available regarding the effectiveness of Zinc and Probiotic combination therapy versus Zinc. This study was designed to compare the efficacy of zincprobiotic combination therapy with zinc therapy alone in reducing the severity of acute diarrhea.

\section{Material and Methods}

We conducted an open, randomized control trial in the pediatric outpatient department of Sub-District Female Hospital, Haldwani (Uttarakhand), from June 2020 till August 2020 for 3-month duration. Inclusion criteria include all children aged six months to 5 years with acute diarrhea, defined as passage of liquid or loose stools at least three times per day lasting for less than or equal to 7 days. Also, Bristol stool criteria $\geq$ type 6[11]. Among exclusion criteria were patients those had received antibiotic, Probiotics or any other anti-diarrheal in the previous $24 \mathrm{~h}$. duration of diarrhea for more than $48 \mathrm{hr}$, blood in stool, severe dehydration requiring hospitalization, severe malnutrition and other chronic diseases, septicemia, bronchopneumonia, cardiac disease, meningitis, immunodeficiency state and not willing to participate in the study. The selected patients were randomly allocated into two groups. Group 1 (Zinc with Probiotic) received oral zinc sulphate $(10 \mathrm{mg} /$ day for less than six months old and $20 \mathrm{mg} /$ day for older than six months old for 14 days along with oral Probiotic for five days), whereas Group 2 received only oral zinc sulphate for 
14 days along with Danger signs explained (fever, refusal to feed, respiratory distress, blood in stool, decreased urination).

In the present study, severity of diarrhea was based on stool frequency (times/day) and duration (hours). Assessment of stool consistency was not considered as it is subjective and difficult to follow a standard parameter. Dysentery was characterized by acute diarrhea mixed with blood, while cholera and diarrhea caused by a rotavirus were characterized by acute watery diarrhea. We suspected cholera if symptoms occurred during known diarrheal outbreaks involving children and adults or frequent, voluminous, loose quickly led to severe dehydration with hypovolemic shock. Parents were advised to follow-up after 48-72hours; those who couldn't come were contacted telephonically to evaluate the response of therapy in terms of remission that is defined as stool passed $<3$ times with regular consistency. Data were analyzed using SPSS software version 21.0. Patient characteristics were reported as means \pm standard deviations, medians (ranges), or $\mathrm{n}(\%)$ as appropriate. For statistical significance, a $p$-value less than 0.05 was considered significant.

\section{Results}

In the present study total number of eligible participants was 110 after fulfilling inclusion and exclusion criteria. However,six patients were excluded (1 Patient developed severe dehydration, five patients left the study) so a total number of patient enrolled was $104 \quad(n=104)$ Patients have divided them into two groups of 52 subjects each: those who received Zinc-Probiotic combination therapy (Group A) and those who received Zinc therapy alone (Group B)Mean age of patients in Group $A$ is $14.02 \pm 13.2$ months and $12.9 \pm 11.4$ months in Group B. Mean weight of patients in Group A is $8.5 \pm 2.7 \mathrm{~kg}$ and $7.8 \pm 2.4 \mathrm{~kg}$ in Group B.

In group A male $62 \%(32) \&$ female $38 \%(20)$ and in group B male $65 \%(34) \&$ female $35 \%$ (18). A greater number of the patients was male in both groups. Fever was present in $48 \%(25)$ of children in Group A as compared to $46 \%(24)$ in group B. Vomiting was present in $46 \%(24)$ in Group A as compared to $37 \%(19)$ in Group B. Considering nutritional assessment (using the WHO classification of weight for age), $80 \%$ (42) of subjects belongs to good nutrition in combination group as compared to $61 \%$ (32) in Zinc-only group.
Malnutrition (both mild and moderate) was observed more in zinc group $23 \%(12), 15.3 \%$ (8) as compare to combination group $7 \%$ (4), $11.5 \%$ (6).

The mean frequency of diarrhea before treatment in Group A was $7.46 \pm 4.1$ times/day as compared to $6.69 \pm 3.6$ times/day in Group B. Mean duration of diarrhea in Group A was $53.5 \pm 30.5$ hours as compared to $57.6 \pm 34.3$ hours in Group B. Mean remission time of diarrhea (time required to form solid stool from watery stool) was $35.7 \pm 19.52$ versus $77.5 \pm 25.4$ hours in group A \& group B respectively. Table 1: Baseline Characteristics of enrolled
patients $(n=104)$

\begin{tabular}{|c|c|c|}
\hline Variables & $\begin{array}{c}\text { Group A (Zinc }+ \\
\text { Probiotics) }(\mathrm{N}=52)\end{array}$ & $\begin{array}{l}\text { Group B (Zinc } \\
\text { only) }(\mathrm{N}=52)\end{array}$ \\
\hline Mean age \pm SD (months) & $14.14 \pm 13.4$ & $12.98 \pm 11.4$ \\
\hline \multicolumn{3}{|l|}{ Gender } \\
\hline Male & $32(61.5 \%)$ & $34(65.3 \%)$ \\
\hline Female & $20(38.4 \%)$ & $18(34.6 \%)$ \\
\hline Mean weight \pm SD $(\mathrm{kg})$ & $8.5 \pm 2.7$ & $7.8 \pm 2.4$ \\
\hline \multicolumn{3}{|l|}{ Feeding history } \\
\hline Age-appropriate & $33(63 \%)$ & $32(61 \%)$ \\
\hline Mismanaged & $19(36 \%)$ & $20(38 \%)$ \\
\hline \multicolumn{3}{|l|}{ Nutritional status } \\
\hline Good & $42(80.7 \%)$ & $32(61.5 \%)$ \\
\hline Mild malnutrition & $4(7 \%)$ & $12(23 \%)$ \\
\hline Moderate malnutrition & $6(11.5 \%)$ & $8(15.3 \%)$ \\
\hline \multicolumn{3}{|l|}{ Mother's Education } \\
\hline No education & $6(11.5 \%)$ & $3(5.7 \%)$ \\
\hline Primary & $7(13.4 \%)$ & $10(19.2 \%)$ \\
\hline HSC & $12(23 \%)$ & $13(25 \%)$ \\
\hline SSC & $21(40.3 \%)$ & $16(30.7 \%)$ \\
\hline Graduate & $6(11.5 \%)$ & $10(19.2 \%)$ \\
\hline \multicolumn{3}{|l|}{ Knows ORS preparation } \\
\hline Yes & $38(73 \%)$ & $42(80.7 \%)$ \\
\hline No & $14(26.9 \%)$ & $10(19.2 \%)$ \\
\hline $\begin{array}{l}\text { Mean frequency of diarrhea } \\
\text { before treatment (times/day) }\end{array}$ & $7.46 \pm 4.1$ & $6.69 \pm 3.6$ \\
\hline $\begin{array}{l}\text { Mean duration of diarrhea } \\
\text { before treatment (hours) }\end{array}$ & $53.5 \pm 30.5$ & $57.6 \pm 34.3$ \\
\hline Mean remission time (hours) & $35.7 \pm 19.52$ & $77.5 \pm 25.4$ \\
\hline
\end{tabular}

\section{Discussion}

In the present study mean age of children with acute diarrhea was14.14 \pm 13.4 months in the combination group as compared to $12.98 \pm 11.4$ months in Zinc only group which is similar to previous studies like Azim M et al., Nguyen TV et al., which suggested that acute diarrhea due to rotavirus is also prevalent in 0-12-month-old 
$[12,13]$. Among gender, more males are predominant in both groups (61.5\% versus $65.3 \%)$, similar to Azim $M$ et al., Hatta $M$ et al., Sultana $M$ et al.[12,14,15]. This male gender predisposition for acute watery diarrhea is still unclear. However, the DHAKA study concluded varied environmental exposures or physiologic biological sex differences could be an underlying mechanism instead of cultural bias in care-seeking behavior that favors boys [16].

The mean weight of both groups was almost similar $(8.5 \pm 2.7$ versus $7.81 \pm 2.4 \mathrm{~kg})$ also with other studies as Azim M et al.(8.21 \pm 2.6 versus $8.09 \pm$ 2.7), Sultana $M$ et al. $(8.6 \pm 1.57$ versus $8.5 \pm 2.16)$ $[12,15]$. Malnutrition increases the risk of severity as well as mortality from common childhood illnesses, including diarrhea. Conversely, diarrhea can also cause acute malnutrition and, if not appropriately addressed, frequent bouts can negatively affect child development and lead to chronic malnutrition [17].In the present study majority of the patient in both groups fall under normal nutrition parameters ( $80.7 \%$ versus $61.5 \%$ ) only.

In the combination group, $7 \%$ and $11.5 \%$ of patients fall under mild to moderate acute malnutrition compare to $23 \%$ and $15.3 \%$ in Zinc only group. In contrast, in Sultana $M$ et al[15] majority of the patient in the combination group fell under mild malnutrition (58.2\%), only $14.5 \%$ were under moderate malnutrition, and in the zinc group,the incidence of mild and moderate malnutrition was similar $30.9 \%$ and $32.7 \%$ respectively. The variability is expected as it depends upon population studies, growth curve used and sample size.

Maternal education is an essential predictor of diarrheal disorder in children. In the present study majority of mothers in both groups were educated till SSC (40.3\% versus $30.7 \%$ ) also $26.9 \%$ in the combination group and $19.2 \%$ in Zinc only group don't know how to prepare ORS, which is a significant risk factor for electrolyte imbalance (hypernatremic and hyponatremic dehydration) which further increase the mortality in acute watery diarrhea. A previous epidemiological study by Desmennu AT also concluded that children with mothers of lower educational attainment have a higher risk of experiencing childhood diarrhea than those whose mothers are better educated as they are involved in practices that benefit the health of their children [18].
In the present study mean duration of diarrhea before treatment was $53.5 \pm 30.5$ hours in the combination group and $57.6 \pm 34.3$ hours in Zinc only group which is similar to Azim M et al. (58.4 \pm 18.67 versus $52 \pm 23.5$ hours) and Aggarwal et al. $(52.08 \pm 30.48$ versus $59.52 \pm 30.72$ hours $)$ $[12,19]$. This was shorter than Hatta $M$ et al. (62.4 \pm 18.67 versus $56 \pm 23.05)$ but longer than Sultana $M$ et al. (30.02 \pm 11.87 versus $28.13 \pm 12.39)$ $[14,15]$.

In the present study, on average, each patient passed $7.46 \pm 4.1$ times of stool before treatment among the combination group and $6.69 \pm 3.6$ times of stool in Zinc only group. In the present study, complete remission was achieved within $35.7 \pm$ 19.52 hours in the combination group, which was faster than inthe zinc-only group $77.5 \pm 25.4$ hours. Similar studies like Sultana $M$ et al., Azim $M$ et al., Hatta $M$ et al. also shown combination therapy was more effective in reducing the severity and early remission of acute watery diarrhea than Zinc alone treatment in children $[15,12,14]$.

\section{Limitation}

The limitation of this study was that etiology was diarrhea was not taken into account. All patients following inclusion criteria attending the outpatient department during the study period were included, which led to selection bias.

\section{Conclusion}

Acute watery diarrhea is the most common preventable cause of morbidity and mortality in developing nations. However, oral rehydration solution and zinc therapy is a standard recommendation by $\mathrm{WHO}$ for management. The recent introduction of probiotics has played a pivotal role in reducing the duration and frequency of diarrhea. This study concludes that combination therapy (Zinc with probiotic) is more effective than zinc therapy alone in reducing the severity, time as well as early resolution of acute diarrhea.

\section{What does this study add to existing knowledge?}

WHO recommends ORS and Zinc as comprehensive management of acute watery diarrhea in children. However, Zinc and Probiotic work by different mechanisms to treat the exact cause; very few studies have compared the effectiveness of combination therapy versus Zinc alone treatment. 
This study demonstrates combination therapy is more effective for decreasing the severity and early resolution of acute watery diarrhea in children. Also, our study has shown a significant association of maternal variables with risk factors for acute watery diarrhea, which are preventable.

\section{Acknowledgements}

The authors would like to thank all the patients and their mothers for participating in the study.

\section{Contributors Detail}

MN: manuscript preparation, acquisition, literature research and statistical analysis; MN, RA: conceptualized, drafted the proposal, analysis, manuscript editing and review, provided intellectual inputs to the manuscript; $M N$ is the guarantor for this paper

\section{Reference}

01. WHO, UNICEF. "End preventable deaths: global action plan for prevention and control of pneumonia and diarrhoea". Geneva: World Health Organization. (2013). [Crossref][PubMed][Google Scholar]

02. Liu L, Oza S, Hogan D, Perin J, Rudan I, Lawn $\mathrm{JE}$, et al. Global, regional, and national causes of child mortality in 2000-13, with projections to inform post-2015 priorities: an updated systematic analysis. Lancet. 2015 Jan 31;385(9966):430-40. doi: 10.1016/S0140-6736(14)61698-6 [Crossref] [PubMed][Google Scholar]

03. Walker CLF, Rudan I, Liu L, Nair $\mathrm{H}$, Theodoratou E, Bhutta ZA, et al. Global burden of childhood pneumonia and diarrhoea. Lancet. $2013 \mathrm{Apr}$ 20;381(9875):1405-16. doi: 10.1016/S0140-67 36(13)60222-6 [Crossref][PubMed][Google Scholar]

04. Das JK, Salam RA, Bhutta ZA. Global burden of childhood diarrhea and interventions. Curr Opin Infect Dis. 2014 Oct;27(5):451-8. doi: $10.1097 / Q C 0.0000000000000096 \quad$ [Crossref] [PubMed][Google Scholar]

05. Brown KH. Diarrhea and malnutrition. J Nutr. 2003 Jan;133(1):328S-332S. doi: 10.1093/jn/133. 1.328S [Crossref][PubMed][Google Scholar]

06. WHO, UNICEF. "WHO-UNICEF Joint statement on the clinical management of acute diarrhea". World Health Assembly, Geneva. (2004). [Crossref] [PubMed][Google Scholar]
07. Guandalini S. Probiotics for prevention and treatment of diarrhea. J Clin Gastroenterol. 2011 Nov;45 Suppl:S149-53. doi: 10.1097/MCG.0b013e3182257e98 [Crossref] [PubMed][Google Scholar]

08. Plaza-Diaz J, Ruiz-Ojeda FJ, Gil-Campos M, Gil A. Mechanisms of Action of Probiotics. Adv Nutr. 2019 Jan 1;10(suppl_1):S49-S66. doi: 10.1093/advances/nmy063. Erratum in: Adv Nutr. 2020 Jul 1;11(4):1054 [Crossref][PubMed][Google Scholar]

09. Allen SJ, Martinez EG, Gregorio GV, Dans LF. Probiotics for treating acute infectious diarrhoea. Cochrane Database Syst Rev. 2010 Nov 10;2010(11):CD003048. doi: 10.1002/14651858.CD003048.pub3. Update in: Cochrane Database Syst Rev. 2020 Dec 8;12:CD003048 [Crossref][PubMed][Google Scholar]

10. Applegate JA, Fischer Walker CL, Ambikapathi R, Black RE. Systematic review of probiotics for the treatment of community-acquired acute diarrhea in children. BMC Public Health. 2013;13 Suppl 3(Suppl 3):S16. doi: 10.1186/1471-2458-13-S3-S16 [Crossref][PubMed][Google Scholar]

11. Lewis SJ, Heaton KW. Stool form scale as a useful guide to intestinal transit time. Scand J Gastroenterol. 1997 Sep;32(9):920-4. doi: $10.3109 / 00365529709011203$ [Crossref][PubMed] [Google Scholar]

12. Azim M A, Doza B, Iqbal S, Chowdhury F, Biswas $\mathrm{S} \mathrm{K}$. Comparative Evaluation on the Effect of ZincProbiotic and Zinc Therapy in Pediatric Acute Gastroenteritis. Chattagram Maa-O-Shishu Hospital Medical College Journal. 19;1(2020):74-77. [Crossref][PubMed][Google Scholar]

13. Nguyen TV, Le Van P, Le Huy C, Weintraub A. Diarrhea caused by rotavirus in children less than 5 years of age in Hanoi, Vietnam. J Clin Microbiol. 2004 Dec;42(12):5745-50. doi: 10.1128/JCM.42.12.5745-5750.2004 [Crossref] [PubMed][Google Scholar]

14. Hatta M, Supriatmo S, Ali M, Sinuhaji A B, Hasibuan B, Nasution F L. Comparison of zincprobiotic combination therapy to zinc therapy alone in reducing the severity of acute diarrhea. Paediatrica Indonesiana. 51;1(2011)1-6. [Crossref] [PubMed][Google Scholar] 
15. Sultana M M, Islam M S, Akhter S, Hossain M B, Mia M S H. Comparative Study of Zinc and Probiotics versus Zinc Alone Therapy in Children with Acute Watery Diarrhea. TAJ: Journal of Teachers Association. 30;2(2017):32-38. [Crossref][PubMed] [Google Scholar]

16. Jarman $A F$, Long $S E$, Robertson $S E$, Nasrin $S$, Alam NH, McGregor AJ, Levine AC. Sex and Gender Differences in Acute Pediatric Diarrhea: A Secondary Analysis of the DHAKA Study. J Epidemiol Glob Health. 2018 Dec;8(1-2):42-47. doi: 10.2991/j.jegh.2018.08.102 [Crossref][PubMed] [Google Scholar]

17. Bulled N, Singer M, Dillingham R. The syndemics of childhood diarrhoea: a biosocial perspective on efforts to combat global inequities in diarrhoearelated morbidity and mortality. Glob Public Health. 2014;9(7):841-53. doi: 10.1080/17441692.2014.924022 [PubMed][Google Scholar]
[Crossref]
18. Desmennu AT, Oluwasanu MM, John-Akinola YO, Oladunni O, Adebowale AS. Maternal Education and Diarrhea among Children aged 0-24 Months in Nigeria. Afr J Reprod Health. 2017 Sep;21(3):2736. doi: 10.29063/ajrh2017/v21i3.2 [Crossref] [PubMed][Google Scholar]

19. Aggarwal S, Upadhyay A, Shah D, Teotia N, Agarwal A, Jaiswal V. Lactobacillus GG for treatment of acute childhood diarrhoea: an open labelled, randomized controlled trial. Indian J Med Res. 2014 Mar;139(3):379-85. [Crossref][PubMed][Google Scholar] 